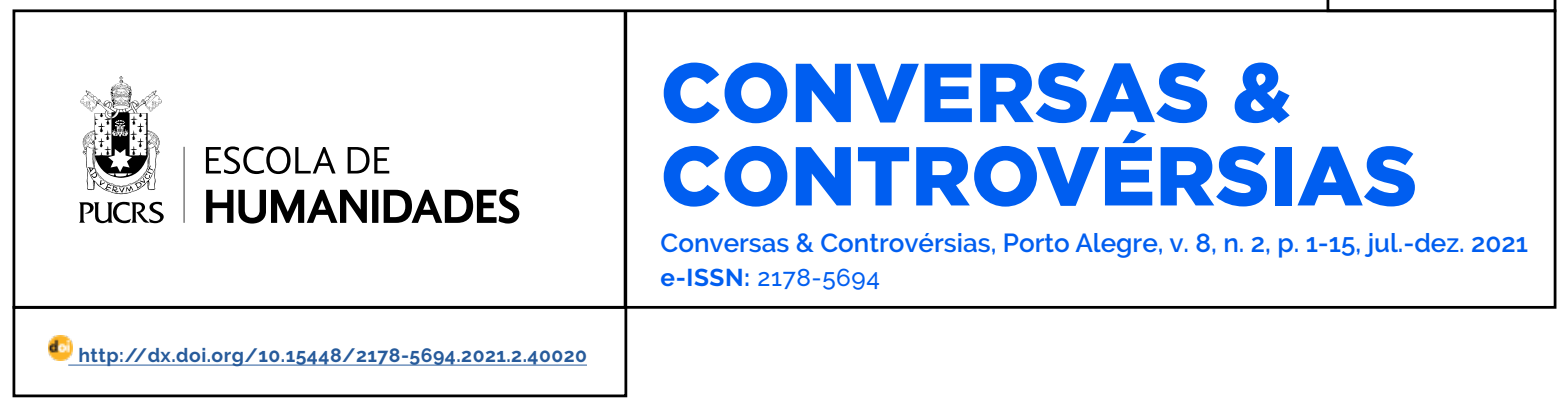

SEÇÃO: DOSSIÊ

\title{
Adesão às normas democráticas como forma de minimizar os efeitos da intolerância política
}

Adherence to democratic norms as a way to minimize the effects of political intolerance

Adherencia a las normas democráticas como forma de minimizar los efectos de la intolerancia politica

\section{Victor Gabriel Menezes Menegassi ${ }^{1}$} orcid.org/0000-0002-6372-655X vgmm235@hotmail.com

\section{Naiara Sandi de \\ Almeida Alcantara ${ }^{2}$} orcid.org/0000-0003-3343-5097 nayara_sandy@hotmail.com

Recebido em: 26/01/2021. Aprovado em: 01/06/2021 Publicado em: 01/12/2021

\section{(c) (i)}

Artigo está licenciado sob forma de uma licença Creative Commons Atribuição 4.0 Internacional.
Resumo: A ascensão de políticos conservadores com atitudes autoritárias, não só no Brasil, como em diversos paises do mundo, pode ser parte da cultural backlash de um grupo social descontente com as recentes mudanças culturais. Esses lideres, pouco aptos ao exercício da governança democrática, estão em consonância com o aumento da intolerância política. À vista disso, nosso objetivo é, justamente, conectar a agenda de pesquisas sobre adesão às normas democráticas e a tolerância, a fim de constatar a existência dessa relação no Brasil. Para isso, utilizamos técnicas de análises quantitativas, através do material empirico fornecido pelo Latin American Public Opinion Project. Partimos da hipótese de que individuos que aderem mais às normas democráticas tendem a ser mais tolerantes em relação aos grupos minoritários. Dentre os resultados, verificamos a existência de relação altamente significativa das variáveis testadas, isto é, os democratas tendem a tolerar mais.

Palavras-chave: Tolerância política. Adesão à democracia. Brasil.

Abstract: The rise of conservative politicians with authoritarian attitudes, not only in Brazil, but in several countries around the world, may be part of the cultural backlash of a social group unhappy with recent cultural changes. These leaders who are not able to exercise democratic governance are in line with the increase in political intolerance. Therefore, our goal is precisely to connect the research agenda on adherence to democratic norms and tolerance, in order to verify the existence of this relationship in Brazil. For this, we use quantitative analysis techniques, through the empirical material provided by the Latin American Public Opinion Project. We start from the hypothesis that individuals who adhere more to democratic norms tend to be more tolerant towards minority groups. Among the results, we verified the existence of a highly significant relationship between the variables tested, that is, Democrats tend to be more tolerate.

Keywords: Political tolerance. Adherence to democracy. Brazil.

Resumen: El surgimiento de políticos conservadores con actitudes autoritarias, no solo en Brasil, sino en varios paises del mundo, puede ser parte de la reacción cultural de un grupo social descontento con los cambios culturales recientes. Estos líderes que no logran ejercer una gobernabilidad democrática están en línea con el aumento de la intolerancia política. En vista de esto, nuestro objetivo es precisamente conectar la agenda de investigación sobre adherencia a las normas democráticas y la tolerancia, para verificar la existencia de esta relación en Brasil. Para ello, utilizamos técnicas de análisis cuantitativo, a través del material empírico proporcionado por el Proyecto de Opinión Pública de América Latina. Partimos de la hipótesis de que los individuos que se adhieren más a las normas democráticas tienden a ser más tolerantes con los grupos minoritarios. Entre los resultados, verificamos la existencia de una relación altamente significativa entre las variables probadas, es decir, los demócratas tienden a tolerar más.

Palabras clave: Tolerancia política. Adherencia a la democracia. Brasil. 


\section{Introdução}

De acordo com Norris e Inglehart (2019), o crescente aumento da intolerância política, não só no Brasil, como em diversos paises do mundo, desemboca na eleição de candidatos que rompem com o padrão das competições partidárias, pois são figuras polarizadoras e sem experiência política, fatos que vão contra ao que pode indicar vitórias eleitorais. Os autores utilizam como caso emblemático Donald Trump, porém essas caracteristicas aplicam-se também a: Silvio Berlusconi, na Itália, Rodrigo Duterte, nas Filipinas, Primeiro Ministro Andrej Babiš e Presidente Milos Zeman, na República Tcheca, Viktor Mihály Orbán, na Hungria, Thaksin Shinawatra, na Tailândia e Hugo Chávez e Nicolás Maduro, na Venezuela.

No Brasil, temos Jair Bolsonaro, que segue o padrão citado, ao mesmo tempo em que não adere às próprias normas democráticas que o levaram a vitória eleitoral, através da postura de desconfiança em relação ao sistema partidário, aos meios midiáticos, ao judiciário, auxiliando, através desse comportamento, na diminuição da confiança social e aumento da intolerância aos principais componentes estruturantes da democracia (Norris e Inglehart 2019).

Esse processo de incubação da crescente intolerância e construção de antagonismos políticos no caso brasileiro, que teve vazão nas eleições de 2018, iniciou-se há, pelo menos, meia década. Segundo Ribeiro e Fuks (2019), desde os protestos de 2013 e, mais enfaticamente, nos de 2015 e 2016 já se podia constatar cisões sociais, que se ilustravam através, inclusive, de comportamentos violentos entre os grupos opositores.

Após a eleição, esse processo de antagonismo continua, tanto a nivel de manifestações, por intermédio de grupos solicitando o fechamento do Supremo Tribunal Federal e a intervenção militar (Falcão e Garcia 2020), quanto a nivel político. Esse último se mostra, por exemplo, através do projeto de lei apresentado pelo deputado federal Eduardo Bolsonaro, que pretende criminalizar a apologia ao comunismo - perseguição essa que, como já indicaram Sullivan, Piereson e Marcus
(1982), é frequentemente relacionada à perseguição a muitos outros grupos, como ateus, negros e liberais - e do chamado "Dossie Antifascista", criado pelo Governo Federal, com informações pessoais de mais de 500 cidadãos e divulgado por um deputado estadual, buscando inflamar os seus seguidores para que perseguissem grupos minoritários e opositores.

Verifica-se que nos paises com longa tradição democrática, especialmente nos Estados Unidos, existe uma vasta literatura que discute a relação entre a adesão à democracia e a tolerância política (Collier e Levistky 1997; Carlin e Singer 2011). Contudo, na América Latina e, especialmente, no Brasil constatou-se uma escassez de estudos nessa área, por isso, neste artigo, pretendemos contribuir para o estado da arte, através da análise de variáveis que podem auxiliar na criação de inferências acerca da relação entre tolerância política e adesão à democracia. Portanto, nosso objetivo principal é responder se há, de fato, relação entre democracia e tolerância no caso brasileiro, assim como já se constatou na América do Norte.

Dentre os objetivos secundários, estão: i) identificar qual o grupo de desafeição dos entrevistados; ii) avaliar os niveis de tolerância política entre os brasileiros, considerando clivagens sociodemográficas; iii) verificar quais são os niveis de adesão normativa à democracia entre essa população. Partimos da seguinte hipótese de pesquisa: individuos que aderem mais às normas democráticas tendem a ser mais tolerantes politicamente, isto é, não apenas afirmam ser esse o melhor sistema para se viver, como também aderem às normas democráticas, como a tolerância à participação, dos mais diferentes grupos, na arena política e a crença nas instituições que edificam a democracia.

O método utilizado foi o quantitativo, através do material empírico fornecido pelo Latin American Public Opinion (LAPOP), e a metodologia será a análise estatistica, através, principalmente, de modelos de regressão linear múltiplos em ambiente de programação. O Survey de Opinião Pública utilizado advém de um projeto do 
LAPOP, o Americas Barometer ${ }^{2}$ que realiza cálculos amostrais representativos em diversos países da América Latina, como o Brasil.

Para responder às questões propostas, bem como cumprir os objetivos elencados, organizamos o artigo da seguinte forma: após o capítulo introdutório, tratamos da literatura clássica acerca da adesão à democracia, em seguida, discutimos sobre tolerância política, utilizando os estudos seminais sobre o tema, para, então, apresentarmos a análise quantitativa, seus resultados e as considerações finais. As principais contribuições do artigo estão na demonstração de que pouco mais da metade dos brasileiros pode ser classificada como ambivalente - contudo, cerca de 33\% são classificados como democratas - , juntamente com a constatação de que existe uma relação altamente significativa entre adesão à democracia e tolerância política, mesmo quando utilizamos mais de uma variável para representar a aderência às normas democráticas.

\section{Adesão normativa à democracia}

Pensando nos valores fundamentais à democracia, como a tolerância à participação plural, Prothro e Grigg (1960) realizaram uma pesquisa nos Estados Unidos, utilizando como amostra comunidades acadêmicas. Dentre os resultados, verificaram alto nivel de concordância (>94\%) com afirmações abstratas e genéricas. Porém, quando esses valores eram analisados em relação a grupos especificos, notou-se expressiva diminuição da concordância, aproximando-se mais da negação dos direitos democráticos. Ademais, verificou-se que as seguintes variáveis afetam positivamente o aumento de adesão às normas democráticas: alta renda, alta escolaridade, residir na região Centro-Oeste (em oposição ao Sul).

Por fim, os autores constataram que a democracia mantém-se, mesmo que não haja consenso geral acerca de determinados valores fundamentais, afinal, é mais proeminente a existência de comportamentos com padrões habituais do que acordos conscientes sobre a os principios democráticos, para manutenção do sistema. Na prática, seria possivel manter uma sociedade democrática e sua estabilidade, ainda que grupos antidemocráticos insistam na negação dos direitos dos grupos opositores (Prothro e Grigg 1960).

Dahl (1961) exemplifica o cenário exposto anteriormente ao citar o exemplo da cidade de New Haven, em Connecticut, em que a população apresentou uma baixa concordância com os valores democráticos, mas a maior parte dos indivíduos não estava disposta a se colocar como oposição às "regras do jogo". Na prática, a maioria seguia as normativas postas pelo regime.

As informações apresentadas podem ser corroboradas pela pesquisa realizada por McClosky (1964), que, através de dados amostrais da população americana, criou dois grupos: a população de maneira geral e as pessoas politicamente engajadas. Através dos grupos, constatou-se que a população geral concorda com os valores democráticos de forma genérica, mas, quando esses valores são aplicados a grupos específicos, a concordância diminui. Já os politicamente engajados (influentials), manifestam-se e identificam-se com uma ideologia liberal democrática mais aprimorada do que o eleitorado geral. Mesmo não sendo compostos por um grupo totalmente homogêneo, seus integrantes compreendem a organização política de maneira mais ordenada e coerente (McClosky 1964).

Parte da explicação para a estabilidade do regime democrático, mesmo frente à inexistência de consenso popular, encontra-se na falta de conhecimento ou indiferença dos grupos sociais, que discordam dos valores quando aplicados aos grupos com os quais não concordam. Ademais, a maioria tende a concordar com os valores quando são analisados de maneira abstrata, por isso, se cria uma imagem de concordância, que inibe conflitos. Contudo, essa explicação também possui um risco, ao mesmo tempo que o pouco entendimento sobre os valores democráticos pode levar a população a agir contra as instituições, sob o pretexto de defendê-las (McClosky 1964).

\footnotetext{
Os questionários são aplicados majoritariamente de maneira bianual, em cerca de 34 paises, desde o ano de 2004. Para mais informações ou para o download dos bancos de dados, acessar: https://www.vanderbilt.edu/lapop/about-americasbarometer.php
} 
As condições necessárias para o surgimento e a manutenção de uma sociedade democrática são, já há bastante tempo, objetos de interesse, estudo e discussão, não só por parte de pesquisadores, mas pelos indivíduos que reconhecem a importância e a superioridade desse regime político. Nos estudos acerca desse tema, um dos primeiros tópicos de discussão é se existe real necessidade de adesão democrática e as normativas, por parte dos individuos, para que esse sistema possa se manter. Discute-se, igualmente, quais são esses valores essenciais à democracia, como deve ser a adesão social, sua intensidade e quais grupos são primordiais à manutenção do sistema (Easton 1975).

É imperioso destacar que o apoio político se manifesta em diferentes dimensões, algumas mais especificas - como o apoio às autoridades políticas, baseado nas percepções de performance das mesmas, sendo menos duradouro - e outras mais difusas - como apoio ao regime político e seus principios fundamentais, mais estável e duradouro. As avaliações positivas ou negativas de uma gestão, como nas tradicionais pesquisas de aprovação, são um tipo de apoio específico, cujos resultados podem mudar em poucas semanas. $A$ confiança e a preferência por um sistema democrático, no entanto, residem em um apoio difuso, considerado mais duradouro. Apesar de distintos, ambos os tipos de apoio citados possuem uma relação de fortalecimento e enfraquecimento mútuo. A título de exemplo, quando o governo apresenta resultados negativos por um periodo temporal contínuo, pode influenciar na diminuição de apoio ao sistema político (Easton 1975).

Geralmente sociedades democráticas contam com lideranças políticas cujo apoio especíico ocorre por determinados grupos e não por outros, afinal, trata-se de uma arena de disputas, com inúmeros interesses heterogêneos. Por essa razão, as autoridades tendem a ser avaliadas das mais diferentes formas, a depender do grupo avaliador. Entretanto, a existência ou não de um consenso, em relação aos valores fundamentais em um regime democrático, é uma discussão que exige mais aprofundamento teórico (Easton 1975).
Diante das questões problemáticas apresentadas, Collier e Levitsky (1997) utilizam a proposição de uma "democracia com adjetivos" para propor uma análise de adesão à democracia levando em consideração determinadas variáveis relevantes para a pesquisa. Ou seja, ao invés de simplesmente agrupar todas as pessoas que aceitam alguns dos principios básicos de uma democracia, mas rejeitam outros, como um único grupo, ou separá-los baseados na posição que ocupam em um índice sobre democracia, a proposta foi criar subtipos de democratas, levando em consideração níveis de concordância e discordância. Para a seleção dos grupos, os autores utilizaram uma amostra composta por mexicanos, os Surveys foram fornecidos pelo National Survey on Political Culture (ENCUP).

Dentre os resultados, verificou-se que a maioria dos mexicanos é ambivalente em relação aos princípios democráticos, ou seja, nem os aceita nem os rejeita totalmente. A análise de clusters levou à criação de seis perfis:

a) democratas liberais, favoráveis à democracia em todas as dimensões analisadas;

b) democratas intolerantes, parecidos com o grupo anterior, mas intolerantes em relação a pontos de vista contrários no espaço público;

c) democratas paternalistas, favoráveis ao governo intervir na liberdade de organização;

d) democratas homofóbicos, que não estendem direitos à homossexuais;

e) democratas excludentes, que preferem a democracia a uma ditadura, mas negam direitos civis às minorias;

f) não-democratas ambivalentes, que não apoiam totalmente a democracia, mas apresentam respostas ambivalentes na maior parte das outras variáveis.

Por fim, os autores concluem que a análise por intermédio de clusters mostra-se útil em medições sobre apoio à democracia, pois permite ordenar diferentes perfis e suas especificidades (Collier e Levistky 1997).

Paralelamente, Schedler e Sarsfield (2007) também criticam a forma como o apoio à democracia 
foi diversas vezes medido, através de questões diretas e abstratas sobre as atitudes em relação à democracia. Além desse, outros problemas são apontados pelos autores, são eles:

i) respostas comumente positivas, pois a democracia é majoritariamente considerada como correta, então muitas respostas positivas podem se enquadrar no que chamamos de "resposta socialmente desejável";

ii) muitas pessoas podem ser favoráveis à democracia por algum aspecto que the agrada, mas essa preferência pode não ter nenhum conteúdo concreto;

iii) a existência de várias concepções de democracia, que podem não coincidir com as concepções dos entrevistados;

iv) as pessoas podem apresentar valores conflituosos, concordando com certos aspectos da democracia, mas discordando de outros.

A partir dos estudos supramencionados, infere-se que a simples concordância com os princípios abstratos não é capaz de indicar real aderência à democracia. Nesse sentido, Booth e Seligson (2009) aprofundam a discussão sobre a legitimidade e a relação do apoio à democracia na manutenção da estabilidade desse regime. Com uma pesquisa piloto em Costa Rica, utilizou-se Surveys, cujas questões foram capazes de captar a multidimensionalidade do apoio político. A finalidade do estudo era identificar a estrutura, as origens e os efeitos da legitimidade na América Latina, região com democracias mais jovens, que não se enquadravam nos modelos teóricos elaborados pela literatura da qual dispunham.

Os autores encontraram seis dimensões estruturais da democracia:

i) Existência de uma comunidade política;

ii) Apoio aos principios fundamentais do regime;

iii) Apoio às instituições do regime;

iv) Avaliação da performance do regime; v) Apoio ao governo local;

vi) Apoio aos atores políticos e autoridades.

As duas primeiras dimensões, mais relacionadas ao apoio difuso, têm um grau de legitimidade significativamente maior do que as outras quatro, dentre as quais, três apresentam valores de legitimidade menores que a metade do índice. As variações também acontecem entre os paises, alguns apresentam grau de legitimidade próximo ao dos EUA e do Canadá (maiores do que qualquer país analisado da América Latina), enquanto outros apresentam valores de legitimidade próximos da metade desses dois paises (Booth e Seligson 2009).

A legitimidade das dimensões, de acordo com os autores, varia porque depende, principalmente, de fatores de nivel individual, como posição social, personalidade e experiências, faixa etária, escolaridade, nivel de formação política, confiança interpessoal, percepção de crime e corrupção, dentre outras, sendo que algumas afetam de maneira positiva, enquanto outras de maneira negativa a legitimidade (Booth e Seligson 2009).

Utilizando o mesmo método da pesquisa citada anteriormente, de Collier e Levitsky em 1997. Carlin e Singer (2011) analisaram o apoio à Poliarquia ${ }^{3}$ na América Latina. O material empírico utilizado foi fornecido pelo LAPOP e, para o desenvolvimento da metodologia, os autores construiram quatro indicadores de apoio à Poliarquia:

i) direito à contestação pública;

ii) participação inclusiva, ou seja, a tolerância em relação a grupos contrários ao regime;

iii) os limites na autoridade do executivo;

iv) o apoio às instituições e aos processos.

Através dos clusters, os autores encontraram cinco perfis de apoio à Poliarquia, além disso, constatou-se que a maior parte dos entrevistados não possuía perfil de democrata ou autoritário, ao invés disso, apresentavam diferentes perfis de apoio à democracia. As questões que variavam entre os perfis foram a renda e a escolaridade, à medida que esses indicadores

3 Termo desenvolvido por Robert Dahl (1971). 
aumentavam, crescia, no mesmo sentido, o apoio aos ideais liberais (Carlin e Singer 2011).

A partir da revisão da literatura acerca da adesão à democracia, verificamos que o apoio aos valores tidos como fundamentais para constituição do regime democrático é analisado pelos Surveys de opinião pública de diferentes formas, ora de maneira genérica e abstrata, ora focada em grupos específicos ou temas de interesse. Muito embora essas pesquisas apresentem distinções no que tange às estruturas das questões, também foram encontrados pontos de convergências, como os itens que compõem os valores chamados de essenciais à manutenção do sistema, um deles é a tolerância política. Por isso, na próxima seção teórica, será apresentada uma breve análise da literatura sobre esse tema, que se tornou tão proeminente diante dos últimos acontecimentos nacionais.

\section{Tolerância política}

O estudo seminal na área de tolerância política foi escrito em 1954, por Samuel Stouffer, que conceitualmente definiu o termo como sendo a permissão dada aos grupos discordantes de participarem politicamente de ações legítimas e legais. O autor estudou as atitudes dos americanos em relação aos grupos alvos daquele período - comunistas, socialistas e ateus - , através de Surveys aplicados pelo American Institute of Public Opinion (AIPO) e pelo National Center for Opinion Research (NORC). Dentre os resultados, constatou-se que os americanos eram majoritariamente intolerantes aos grupos minoritários analisados, pois eram incapazes de permitir que seus opositores exercessem direitos sociais, como lecionar em escolas públicas, trabalhar como balconista e falar em público.

Além da constatação de alta intolerância, o autor buscou identificar as variáveis preditoras desse sentimento. Seu mapeamento mostrou que o sentimento de ameaça, bem como a educação, eram fortes preditoras, a primeira em uma relação diretamente proporcional, enquanto a segunda mostrou-se inversamente proporcional. Isto é, quanto mais cresce o sentimento de ameaça, maior tende a ser a intolerância, enquanto o aumento da escolaridade age no sentido inverso, auxiliando no aumento da capacidade de tolerar (Stouffer 1955).

Os estudos subsequentes, como de Prothro e Grigg (1960), já indicavam que a negação de direitos a grupos específicos parecia refletir mais a desafeição que os entrevistados sentem por esses grupos, do que a negação desses valores em si. Sendo assim, parece razoável inferir que os entrevistados possuem objeções a determinados grupos minoritários, em relação à liberdade, para exercício dos direitos sociais.

MCClosky (1964), buscando explicações para as divergências encontradas em sua pesquisa citada anteriormente, apresentou, como uma das conclusões, os aspectos racionais e ideológicos que muitas vezes são superestimados, já que outras forças podem ter um papel mais importante na formação da ideologia do que a crença em uma doutrina política. Isso parece explicar a inconsistência quanto às respostas democráticas nas afirmações abstratas, já as respostas consideradas como antidemocráticas, que dizem respeito aos direitos de determinados grupos least likead - como comunistas, negros e ateus - e a negação de direitos a esses individuos, podem ser entendidas como uma tentativa de manutenção de seu estilo de vida conservador.

De maneira geral, tanto Prothro e Grigg (1960) quanto MCClosky (1964) e outros autores realizaram pesquisas com a utilização do mesmo método de análise pensado inicialmente por Stouffer (1950) e, ao replicarem os Surveys com os mesmos grupos alvos, chegaram a resultados semelhantes. Todavia, à medida que essa pesquisa permaneceu sendo replicada, percebeu-se que os niveis de intolerância estavam diminuindo (Lawrence 1976). Diante desse cenário, autores como Davis (1975) e Nunn, Crockett e Allen (1978) tentaram explicar o aumento da tolerância com base nas mudanças contextuais dos Estados Unidos, isto é, à medida que certos fatores sociais se alteraram, como a expansão da educação e da comunicação, a população estava tornando-se mais tolerante.

Sullivan, Piereson e Marcus (1982) buscaram explicações divergentes das apresentadas até 
aquele momento, por isso, possuem papel central na discussão sobre tolerância política. Os autores constataram que, desde Stouffer (1955), a maior parte das pesquisas que se propunha a estudar 0 tema replicava o mesmo método de análise, mas, com o tempo, esse método tornou-se obsoleto, afinal, os contextos políticos estavam mudando. A sociedade passou por transformações e novos grupos alvos de desafeição surgiram, logo, não era mais adequado permanecer estudando tão somente os comunistas, ateus e socialistas (Sullivan, Piereson e Marcus 1982).

Por isso, os autores propuseram o método de análise que foi chamado de least liked, em que primeiro o entrevistado deveria identificar o grupo (ou os grupos) de maior desafeição e, só em seguida, seria inquirido quanto aos direitos políticos do grupo previamente escolhido. Ao aplicar esse modelo de análise, constatou-se que, diferente do que pesquisas anteriores estavam apresentando, o nivel de tolerância não estava aumentando, isto é, a intolerância mantinha-se alta, o que mudou foram os grupos alvos, que ao longo das décadas tornaram-se mais plurais (Sullivan, Piereson e Marcus 1982).

Investigando as variáveis que influenciam no ato de tolerar, constatou-se a existência de três principais grupos explicativos: i) questões sociais; ii) psicológicas; iii) políticas. No primeiro ponto, a educação, idade, religião e renda mostraram-se importantes; no segundo, constatou-se a importância da confiança interpessoal, da autoestima, e do sentimento de ameaça; por fim, politicamente, os democratas tendiam a ser mais tolerantes do que os republicanos (Sullivan, Piereson e Marcus 1982).

Linz e Diamond (1989) discutem sobre a democracia na América Latina, a partir de uma perspectiva economicista, demonstrando que, ao retornar aos moldes democráticos, em 1980, os países latino-americanos estavam em situação econômica ruim, com a diminuição da renda individual e per capita. O Brasil, apesar de inicialmente ter evitado um desastre econômico, em 1987 também apresentava altas taxas de desemprego e baixos salários, dentre outras mazelas sociais. Nesses cenários, as instituição que compõem o Estado democrático passaram a sofrer danos causados pela situação econômica; frente a isso governos populistas aparecem como uma possivel solução a curto prazo, o contraponto seria o enfraquecimento das instituição. Por isso, foi proeminente que àquela geração, do final do século XX, em suas diferentes camadas sociais, recém saida de regimes autoritários, optasse pela manutenção dos valores democráticos, como a tolerância. Segundo os autores:

"Democracy might not be the ideal regime and it might not be able to solve all problems, but we suspect the fate of most of the new democracies of Latin America will be to make their present democratic institutions work as well as possible". (Linz e Diamond 1989, 52).

Essa compreensão, de que ainda que não seja um regime perfeito, é melhor do que outras experiências autoritárias e foi importante para a valorização dos seus alicerces.

Sullivan e Transue (1999), analisando questões psicológicas, confiança interpessoal e o capital social em relação à democracia, corroboraram alguns dos achados de Diamond e Linz (1989). Os autores demonstram que o desenvolvimento dessas variáveis intervenientes, supramencionadas, são importantes para o apoio democrático. Ademais, outras variáveis, como a tolerância política a participação, estão diretamente relacionadas com a edificação do regime. A primeira, porque democracias mais robustas possuem individuos com maior confiança interpessoal e que, consequentemente, se sentem menos ameaçados por ideias discordantes, sendo assim, capazes de tolerar grupos impopulares no cenário político. Já a segunda, trata-se da confirmação do que pesquisas precursoras, desde Stouffer (1955), já demonstraram, que a elite política tende a ser um pouco mais tolerante, do que o cidadão que não participa da arena política. Ou seja, a participação em espaços mais plurais tende a aumentar a capacidade de tolerar grupos divergentes.

Em 1995 Sullivan et al. propuseram a tese da diminuição da intolerância frente ao surgimento de alvos múltiplos, isto é, o aumento de grupos alvos de desafeição faria com que a intolerância fosse 
dissipada. Testando essa tese, Gibson (2008, 2009) demonstrou que, de fato, houve uma diminuição das atitudes de intolerância entre os americanos. Todavia, isso não se deu em razão da pluralização dos grupos alvos, ao contrário, à medida que outros grupos minoritários tornam-se pauta de discussões públicas - como é o caso das mulheres, negros, homossexuais -, o foco da intolerância deixa de ser os grupos que anteriormente eram tidos como mais perniciosos socialmente (comunistas, socialistas e ateus). Entende-se que à medida que a intolerância voltada a certos grupos diminui, aumenta em relação a outros.

Um exemplo desse cenário foi o 11 de setembro nos EUA, o ataque terrorista ocorrido em 2001, cuja a autoria foi atribuida aos extremistas mulçumanos, que tornou todo um grupo social, imediatamente, alvo de intolerância. Esse novo grupo não necessariamente seria composto por mulçumanos extremistas, mas por qualquer individuo que se assemelhasse aos estereótipos impostos aos praticantes do islã. Essas pessoas passaram a representar uma ameaça, real ou imaginária, à segurança pública (Gibson 2008). Nesse contexto de preconceitos e intolerâncias, faz-se necessário ressaltar que a literatura (Gibson 2009) já demonstrou haver uma distinção entre comportamentos preconceituosos e atitudes intolerantes. O segundo termo está muito mais relacionado ao sentimento de ameaça pessoal que determinados grupos podem representar, como já dito. Por isso, a exposição aos processos democráticos tende a ser uma variável capaz de aumentar a tolerância, ao passo que os cidadãos compreendem a necessidade de convivência com as ideias concorrentes.

Conforme já mencionado, ao realizar o levantamento da literatura que discute sobre o tema, constatamos a existência de poucos estudos na América Latina, e menos ainda que discutam, especificamente, sobre o Brasil. Em 2010, Ribeiro utilizou Surveys do World Values Surveys (WVS) para estudar a tolerância política como variável independente na discussão sobre ensinamentos a serem transferidos aos filhos e constatou que $35 \%$ dos brasileiros acreditava que esse era um importante valor a ser ensinado. Outra análise re- alizada foi acerca dos grupos considerados mais objetáveis e, para testar a variável, foi pedido ao entrevistado para escolher aqueles que menos gostasse, dentre a seguinte lista:

1) pessoas de outras raças;

2) pessoas com Aids;

3) trabalhadores imigrantes ou estrangeiros;

4) homossexuais;

5) pessoas de outras religiões.

Os resultados demonstraram que os menos gostados foram os homossexuais e as pessoas com Aids (Ribeiro 2010).

Mais recentemente, Ribeiro e Borba (2019) utilizaram o material empírico fornecido pelo LAPOP, para analisar a tolerância política no Brasil, entre 2006 e 2014, tendo como principal interveniente a escolaridade. Para o teste da tolerância, os autores criaram um Índice de Tolerância Política, composto por um conjunto de variáveis relacionadas à aceitação de direitos a um grupo que o entrevistado não gosta. Ao testarem esse indice em relação a uma série de variáveis sociodemográficas, constataram que a aderência aos conceitos abstratos da democracia tende a aumentar a tolerância, assim como a escolaridade, já a idade mostrou ser inversamente proporcional. As variáveis que não apresentaram significância foram: posicionamento ideológico, indice de apoio às instituições, sensação de segurança e o sexo (Ribeiro e Borba 2019).

Os estudos brasileiros citados são os precursores na área de tolerância e discutem questões essenciais acerca do tema. Todavia, nota-se que essa ainda é uma área incipiente, à vista disso, este artigo pretende contribuir com o aumento de estudos para o estado na arte, a nivel nacional, por isso, nossa proposta é discutir a relação entre a tolerância política e as normas democráticas, utilizando um Survey, aplicado recentemente, a uma amostra capaz de representar o cenário nacional.

\section{Metodologia}

A metodologia utilizada foi a quantitativa, através do material empírico fornecido pelo AmericasBa- 
rometer, projeto do LAPOP, rodada de 2017, cuja a amostra é composta por 1532 individuos, portanto, trata-se de uma pesquisa representativa a nivel nacional. Escolhemos trabalhar somente com essa rodada, porque, de forma inédita, são apresentadas questões sobre tolerância política no contexto brasileiro, que utilizam as orientações gerais propostas por Sullivan, Piereson e Marcus (1982). Na rodada seguinte essas questões não foram repetidas.

A primeira bateria de questões selecionadas tem como objetivo identificar qual o grupo de desafeição dos entrevistados:

Falando de alguns grupos de pessoas, poderia informar o quanto gosta ou desgosta dos listados abaixo. Usaremos, agora, uma escala de 1 a 10, na qual 1 significa "desgosto muito" e 10 significa "gosto muito".

BRAGRUP1. Pessoas que defendem a legalização do aborto:

BRAGRUP2. Pessoas que defendem o regime militar;

BRAGRUP3. Comunistas;

BRAGRUP4. Petistas/Simpatizantes do PT;

BRAGRUP 5. PSDBistas/Simpatizantes do PSDB. (Dicionário de Código, LAPOP, 2017).

O grupo alvo foi, então, identificado mediante verificação daquele com menor nota na escala de gosto. Nos casos em que o entrevistado atribuiu a menor pontuação a mais de um grupo, o empate foi resolvido por designação aleatória. A partir dessa identificação, os entrevistados foram perguntados quanto a seus posicionamentos em relação à fruição de alguns direitos políticos por parte do grupo de maior desafeição:

Falando do grupo de pessoas que o(a) sr./sra menos gosta...

Em uma escala de 1 a 10, na qual 1 significa "desaprova fortemente" e 10 significa "aprova fortemente"...

BRAD8. O quanto o sr./sra. aprova o direito dessas pessoas de votar?

BRAD9. O quanto o sr./sra. aprova o direito dessas pessoas de fazer um discurso público?

BRAD10. O quanto o sr./sra. aprova o direito dessas pessoas de concorrer a um cargo público? (Dicionário de Código, LAPOP, 2017).

As respostas a essas três questões sobre tolerância política foram agrupadas em um Índice de Tolerância Política (com alpha de Cronbach de 0,85), padronizado para variar entre 1 e 10. Foram considerados "intolerantes" os que apresentaram valores entre 1-3, "moderados" os que apresentaram valores entre 3-8 e "tolerantes" os que apresentaram valores entre 8-10. Além da questão sobre tolerância política, foram selecionadas duas questões que dizem respeito à adesão normativa à democracia. A primeira, seguindo um modelo clássico, é conhecida como churchilliana e apresenta a seguinte redação:

ING4. Mudando de assunto de novo, a democracia tem alguns problemas, mas é melhor do que qualquer outra forma de governo. Até que ponto concorda ou discorda desta frase? (Dicionário de Código, LAPOP, 2017).

O entrevistado deveria se manifestar quanto à concordância com essa afirmação, dentro de uma escala de 1 a 7, em que 1 significa "discorda muito" e 7 significa "concorda muito". A partir disso, foi criada uma classificação tricotômica, que fazem parte: os não-democratas (responderam com 1 ou 2), os ambivalentes (responderam com 3, 4 ou 5) e os democratas (responderam com 6 ou 7).

Enquanto a "churchilliana" representa um tipo de apoio mais genérico e abstrato, a questão a seguir pede que os entrevistados respondam se consideram ou não que um golpe militar seja justificado em determinado contexto, ou seja, trata de um valor central do pensamento democrático: o respeito aos ritos processuais e institucionais da escolha de governantes, processo frequentemente chamados de rules of the game.

O enunciado apresenta a seguinte formulação:

Algumas pessoas dizem que, em certas circunstâncias, se justificaria que os militares tomassem o poder através de um golpe de Estado. Na sua opinião, se justificaria um golpe militar... (Dicionário de Código, LAPOP, 2017).

A amostra, então, foi dividida da seguinte forma: metade teve que responder se um golpe seria justificado "JC10. Quando há muito crime" e a outra metade se o ato se justificaria "JC13. Diante de muita corrupção". Independentemente de qual a justificativa (crime ou corrupção), as alternativas de respostas eram as mesmas: 
"(1) seria justificado que os militares tomassem o poder por um golpe de estado" e "(2) não se justificaria que os militares tomassem o poder por um golpe de estado".

Para a análise, ambos os grupos foram fundidos em um único, em que são considerados democratas os que não acham um golpe militar justificado e não-democratas os que acham que um golpe militar seria justificado.

Também, foram incluidas variáveis sociodemográficas (Quadro 1) para identificar possiveis diferenças entre tolerância política e adesão normativa à democracia, considerando essas diferentes clivagens.

Quadro 1 - Informações sobre as variáveis sociodemográficas selecionadas.

\begin{tabular}{|c|c|}
\hline Sexo & Dicotômica: Homem (1) e Mulher (2) \\
\hline Faixa Etária & $\begin{array}{l}\text { Variável de idade recodificada em cinco faixas etárias: De } 16 \text { a } 24 \text { anos; de } 24 \\
\text { a } 34 \text { anos; de } 35 \text { a } 44 \text { anos; de } 45 \text { a } 60 \text { anos; e Mais de } 60 \text { anos. }\end{array}$ \\
\hline $\begin{array}{c}\text { Faixa de } \\
\text { Renda }\end{array}$ & $\begin{array}{l}\text { Variável criada a partir da junção de várias faixas de renda originais, } \\
\text { reduzidas em quatro: Até R\$ } 1050 \text {; de R\$1051 até R\$ 3150; de R\$ } 3151 \text { até } \\
\text { R\$ } 4950 \text {; e Maior de R\$ } 4951 .\end{array}$ \\
\hline Escolaridade & $\begin{array}{l}\text { Variável de anos de estudo recodificada em quatro valores de escolaridade: } \\
\text { Nenhuma ( } 0 \text { anos de estudo); Baixa (entre } 1 \text { e } 8 \text { anos de estudo); Média } \\
\text { (entre } 9 \text { e } 11 \text { anos de estudo); e Alta (mais que } 12 \text { anos de estudo). }\end{array}$ \\
\hline
\end{tabular}

Fonte: Autores, a partir do LAPOP, 2017.

Os niveis de tolerância política entre os brasileiros foram descritos considerando as clivagens sociodemográficas. O mesmo foi feito entre ambas as variáveis de adesão normativas à democracia. Por último, foram feitas regressões lineares, com o objetivo de identificar e quantificar as relações entre tolerância política (variável dependente) e adesão normativa à democracia, considerando, também, as clivagens sociodemográficas. Na regressão linear, a variável de apoio à democracia (churchilliana) foi utilizada em sua forma original, com escala de 1 a 7.

\section{Resultados}

Para facilitar o entendimento, as células com os maiores valores foram destacadas. A Tabela 1 apresenta os niveis de tolerância política entre o público brasileiro. Mais da metade da amostra faz parte do grupo dos "moderados", em seguida aparecem os "tolerantes", com quase 30\% e, por último, os "intolerantes", com 17,56\%.
TABELA 1 - Tolerância política no Brasil em 2017 (\%) $(n=1498)$.

\begin{tabular}{ccc}
\hline Intolerantes & Moderados & Tolerantes \\
17,56 & $\mathbf{5 3 , 0 0}$ & 29,44 \\
\hline
\end{tabular}

Fonte: Autores, a partir do LAPOP, 2017.

Já a Tabela 2, apresenta a quantidade de cada uma dessas categorias de tolerância, relacionadas com as variáveis sociodemográficas. As variáveis "sexo" e "faixa de renda" não se mostraram significantes. A escolaridade se mostrou relevante entre os entrevistados com ensino superior, já que esse grupo mostrou-se mais tolerante. A faixa etária se mostrou significativa, e constatou-se que o grupo etário mais tolerante é formado por jovens. 
TABELA 2 - Tolerância política com clivagens sociodemográficas no Brasil em 2017.

\begin{tabular}{|c|c|c|c|}
\hline \multirow{2}{*}{ Variáveis } & \multicolumn{3}{|c|}{ Tolerância Politica } \\
\hline & Intolerantes $(\%)$ & Moderados (\%) & Tolerantes (\%) \\
\hline \multicolumn{4}{|l|}{ Sexo } \\
\hline Masculino & 17,22 & 52,07 & 30,71 \\
\hline \multirow{2}{*}{\multicolumn{4}{|c|}{$\mathrm{N}-1498 / \mathrm{p}$-valur $-0,34313$}} \\
\hline \multicolumn{2}{|l|}{ Faixa Etária } & & \\
\hline De 16 a 24 anos & 9,38 & 55,13 & 35,49 \\
\hline De 24 a 34 anos & 14,16 & 52,31 & 33,53 \\
\hline De 35 a 44 anos & 20,38 & 53,50 & 26,12 \\
\hline De 45 a 60 anos & 24,37 & 50,70 & 24,93 \\
\hline Mais de 60 anos & 22,14 & 54,29 & 23,57 \\
\hline \multicolumn{4}{|c|}{$\mathrm{N}=1498 / \mathrm{p}$-valor $<0,000001$} \\
\hline $\begin{array}{l}\text { Faixa de Renda } \\
\text { Até R\$ } 1050\end{array}$ & 15,92 & 54,56 & 29,52 \\
\hline $\begin{array}{r}\text { De RS } 1051 \text { ate } \\
\text { RS } 3150\end{array}$ & 18.13 & 53,67 & 28,20 \\
\hline $\begin{array}{r}\text { De RS } 3151 \text { até } \\
\text { RS } 4950\end{array}$ & 15,45 & 55,45 & 29,10 \\
\hline Maior de RS 4951 & 16,67 & 45,83 & 37,50 \\
\hline \multicolumn{4}{|c|}{$\mathrm{N}-1416 /$ p-valor $=0,89197$} \\
\hline \multicolumn{4}{|l|}{ Escolaridade } \\
\hline Nenhuma & 25,00 & 58,33 & 16,17 \\
\hline Baixa & 18,74 & 53,76 & 27.50 \\
\hline Média & 16,30 & 54,70 & 29,00 \\
\hline Alta & 17,57 & 40,54 & 41,89 \\
\hline \multicolumn{4}{|c|}{$\mathrm{N}=1467 / \mathrm{p}$-valor $=0,01079$} \\
\hline
\end{tabular}

Fonte: Autores, a partir do LAPOP, 2017.

Sobre os niveis de apoio à democracia, podemos notar, através da Tabela 3, que mais da metade dos brasileiros pode ser classificada como "ambivalente", enquanto os "democratas" apresentam o dobro da quantidade dos "não-democratas".

TABELA 3 - Apoio à democracia (Churchilliana) no Brasil em 2017 (\%) (n=1505).

\section{Não-democrata Ambivalente Democrata $\begin{array}{lll}16,21 & \mathbf{5 0 , 7 0} & 33,09\end{array}$}

Fonte: Autores, a partir do LAPOP, 2017

Na Tabela a verificamos a quantidade de cada uma dessas categorias de apoio à democracia relacionadas com as variáveis sociodemográficas. Todas as variáveis testadas se mostraram significativas. Ser homem mais velho apresentou relação com maior nivel de apoio à democracia. A faixa de renda e a escolaridade se mostraram ainda mais significativas, sendo relacionadas ao apoio à democracia.
TABELA 4 - Apoio à democracia (churchilliana) com clivagens sociodemográficas, no Brasil, em 2017.

\begin{tabular}{|c|c|c|c|}
\hline \multirow{2}{*}{ Variáveis } & \multicolumn{3}{|c|}{ Apoio à democracia } \\
\hline & Não-democrata (\%) & Ambivalente (\%) & Democrata (\%) \\
\hline \multicolumn{4}{|l|}{ Sexo } \\
\hline Masculino & 15,83 & 47,87 & 36,30 \\
\hline Feminino & 16.60 & 53,52 & 29.88 \\
\hline \multicolumn{4}{|c|}{$\mathrm{N}-1505 / \mathrm{p}$-valor $-0,029539$} \\
\hline \multicolumn{4}{|l|}{ Faixa Etária } \\
\hline De 16 a 24 anos & 14,46 & 59,29 & 26,25 \\
\hline De 24 a 34 anos & 17,87 & 47.26 & 34,87 \\
\hline De 35 a 44 anos & 17,04 & 52,68 & 30,28 \\
\hline De 45 a 60 anos & 15,60 & 46.52 & 37,88 \\
\hline Mais de 60 anos & 16,08 & 44,76 & 39,16 \\
\hline \multicolumn{4}{|c|}{$\mathrm{N}=1505 / \mathrm{p}$-valor $=0,023223$} \\
\hline \multicolumn{4}{|l|}{ Falxa de Renda } \\
\hline Até RS 1050 & 21,35 & 52,50 & 26,15 \\
\hline $\begin{array}{r}\text { De RS } 1051 \text { até } \\
\text { RS } 3150\end{array}$ & 12,91 & 55,09 & 32,00 \\
\hline $\begin{array}{r}\text { De RS } 3151 \text { até } \\
\text { RS } 4950\end{array}$ & 14,55 & 37,27 & 48,18 \\
\hline $\begin{array}{r}\text { Maior de RS } \\
4951\end{array}$ & 9,28 & 39,17 & 51,55 \\
\hline \multicolumn{4}{|c|}{$\mathrm{N}=1424 / \mathrm{p}$-valor $<0,000001$} \\
\hline \multicolumn{4}{|l|}{ Escolaridade } \\
\hline Nenhuma & 16,66 & 54,17 & 29,17 \\
\hline Baixa & 19,89 & 50,44 & 29,67 \\
\hline Média & 15,43 & 53,58 & 30,99 \\
\hline Alta & 6,76 & 35,81 & 57,43 \\
\hline \multicolumn{4}{|c|}{$\mathrm{N}=1471 / \mathrm{p}$-valor $<0,000001$} \\
\hline
\end{tabular}

Fonte: Autores, a partir do LAPOP, 2017.

Testamos, igualmente, a opinião dos entrevistados quanto a apoiar um golpe, em caso de crime ou de corrupção, e os resultados (Tabela 5) demonstraram que a maior parte das pessoas tende a ser contra um golpe.

TABELA 5 - Apoio ao golpe militar no Brasil em $2017(\%)(n=1424)$.

\section{Favorável Contrário

$36,03 \quad \mathbf{6 3 . 9 7}$

Fonte: Autores, a partir do LAPOP, 2017.

Relacionando os indivíduos favoráveis e contrários a um golpe militar com as variáveis sociodemográficas, verificamos, conforme a Tabela 6 , que as variáveis "sexo" e "renda" não se mostraram significantes, enquanto a faixa etária e a escolaridade apresentaram significância estatística. Portanto, constatamos a existência de uma correlação entre ser jovem com alta escolaridade e a tendência por rejeitar um golpe militar. 
TABELA 6 - Apoio ao golpe militar com clivagens sociodemográficas no Brasil, em 2017.

\begin{tabular}{|c|c|c|}
\hline \multirow{2}{*}{ Variáveis } & \multicolumn{2}{|c|}{ Apoio ao golpe militar } \\
\hline & Favorável (\%) & Contrário (\%) \\
\hline Sexo Masculino & 38,04 & 61,96 \\
\hline Feminino & 33.90 & 66,10 \\
\hline \multicolumn{3}{|c|}{$\mathrm{N}=1424 / \mathrm{p}$-valor $=0,10382$} \\
\hline \multicolumn{3}{|l|}{ Faixa Etária } \\
\hline De 16 a 24 anos & 33,23 & 66,77 \\
\hline De 24 a 34 anos & 29,22 & 70,78 \\
\hline De 35 a 44 amos & 34,56 & 65,44 \\
\hline De 45 a 60 anos & 42,48 & 57,52 \\
\hline Mais de 60 anos & 46,62 & 53,38 \\
\hline \multicolumn{3}{|c|}{$\mathrm{N}=1424 / \mathrm{p}$-valor $<0,00015$} \\
\hline \multicolumn{3}{|c|}{ Faixa de Renda } \\
\hline Até R\$ 1050 & 38,38 & 61,62 \\
\hline $\begin{array}{r}\text { De R\$ } 1051 \text { até } \\
\text { R\$ } 3150\end{array}$ & 34,84 & 65,16 \\
\hline $\begin{array}{r}\text { De R\$ } 3151 \text { até } \\
\text { R\$ } 4950\end{array}$ & 37,38 & 62,62 \\
\hline $\begin{array}{r}\text { Maior de RS } \\
4951\end{array}$ & 30,21 & 69,79 \\
\hline \multicolumn{3}{|c|}{$\mathrm{N}=1348 / \mathrm{p}$-valor $=0,16278$} \\
\hline \multicolumn{3}{|l|}{ Escolaridade } \\
\hline Nenhuma & 56,52 & 43,48 \\
\hline Baixa & 40,72 & 59,28 \\
\hline Média & 34,05 & 65,95 \\
\hline Alta & 24,49 & 75,51 \\
\hline \multicolumn{3}{|c|}{$\mathrm{N}=1394 / \mathrm{p}$-valor $<0.00005$} \\
\hline
\end{tabular}

Fonte: Autores, a partir do LAPOP, 2017.

Por fim, a Tabela 7 apresenta o resultado de duas regressões lineares, ambas utilizando o Índice de Tolerância Política como variável dependente e as variáveis sociodemográficas como independentes. Um dos testes utiliza como variável independente o apoio à democracia (churchilliana), no outro teste empregamos o uso da variável de apoio a um golpe militar. As variáveis "sexo", "faixa de renda" e "escolaridade" não se mostraram significativas, enquanto a faixa etária foi altamente significativa, isto é, os mais idosos tendem a ser mais intolerantes, enquanto os democratas e os contrários ao golpe devem ser mais tolerantes.
TABELA 7 - Regressões lineares múltiplas testando tolerância política.

\begin{tabular}{|c|c|c|}
\hline Preditores & Índice de Tole & rância Política \\
\hline (Intercepto) & $\begin{array}{c}5.54 * * * \\
(0.47)\end{array}$ & $\begin{array}{c}6.20 * * * \\
(0.48)\end{array}$ \\
\hline Sexo & $\begin{array}{l}-0.00 \\
(0.15)\end{array}$ & $\begin{array}{c}0.03 \\
(0.15)\end{array}$ \\
\hline Faixa Etária & $\begin{array}{c}-0.31 * * * * \\
(0.06)\end{array}$ & 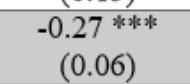 \\
\hline Faixa de Renda & $\begin{array}{l}-0.05 \\
(0.09)\end{array}$ & $\begin{array}{c}0.02 \\
(0.10)\end{array}$ \\
\hline Escolaridade & $\begin{array}{c}0.06 \\
(0.12)\end{array}$ & $\begin{array}{c}0.17 \\
(0.12)\end{array}$ \\
\hline Churchilliana & $\begin{array}{c}0.32 * * * \\
(0.04)\end{array}$ & \\
\hline Golpe & & $\begin{array}{l}0.36 * \\
(0.16)\end{array}$ \\
\hline Observações & 1374 & 1310 \\
\hline $\begin{array}{l}\mathbf{R}^{2} / \mathbf{R}^{2} \\
\text { ajustado }\end{array}$ & $0.065 / 0.062$ & $0.026 / 0.022$ \\
\hline
\end{tabular}

Fonte: Autores, a partir do LAPOP, 2017.

Constatamos, através dos dados expressos nas Tabelas 1 e 3 que a maior parte da população é moderada/ambivalente em relação ao apoio à democracia e à tolerância politica, conforme esperado, tendo em vista que estudos anteriores já apontavam esses mesmos resultados (Moises 2008; Casalecchi 2016; Fuks et al. 2016; Fuks, Casalecchi e Ribeiro 2019; Ribeiro e Fuks 2019).

A Tabela 2 mostrou que a escolaridade, de fato, tem relação com a tolerância política, especialmente quando se compara os respondentes com nivel superior em detrimento daqueles sem essa escolaridade. A faixa etária se mostrou altamente significativa e relevante, variável essa que não aparece com grande relevância em pesquisas anteriores (Sullivan, Piereson e Marcus 1982). Conforme a idade aumenta, a intolerância também tende a aumentar, enquanto as variáveis de sexo e faixa de renda não se mostraram significativas.

A Tabela 4, que trata do apoio à democracia (churchilliana), indica que todas as variáveis sociodemográficas utilizadas têm relação com o apoio à democracia. O sexo masculino mostrou maior tendência em ser democrata, a faixa etária apresentou significância, e seu crescimento está inversamente relacionado à tolerância, isto é, con- 
forme aumenta uma variável a outra diminui, por isso, segundo os resultados, apesar dos idosos serem mais intolerantes, tendem, igualmente, a ter comportamentos mais democratas que as demais faixas de idade. Esse resultado pode indicar que a concordância com uma afirmação genérica e abstrata não representa o apoio aos princípios democráticos fundamentais, como indicaram Prothro, Grigg (1960) e McClosky (1964). Já as relações entre democracia e tolerância política, não são tão simples e lógicas, pelo contrário, são multidimensionais e contraditórias (Schedler e Sarsfield 2007; Booth e Seligson 2008; Sullivan, Piereson e Marcus 1982; Gibson 2006).

A escolaridade e a faixa de renda se mostraram muito significativas para o apoio à democracia. Esse primeiro resultado já era indicado pela literatura, enquanto o segundo se mostrou mais relevante do que já fora constatado teoricamente (Booth e Seligson 2008). Os resultados da Tabela 5 indicaram que, mesmo sendo ambivalentes em relação à democracia, a maior parte da população rejeita um golpe militar em caso de crime ou de corrupção, especialmente os com maior escolaridade e mais jovens (Tabela 6).

Finalmente, a última tabela apresenta os resultados da regressão linear, que teve como objetivo descobrir as relações entre adesão à democracia e tolerância política. O sexo, a faixa de renda e a escolaridade não se mostraram significantes. A variável de escolaridade apresentou significância na Tabela 2, isso significa que a inclusão de novas variáveis diminuiu a importância da variável testada através de análise bivariada. Conforme já verificado na Tabela 2, a faixa etária mostrou-se altamente significativa.

Concluindo a análise do teste de regressão, inferimos que ambas as variáveis de adesão à democracia (churchilliana e apoio ao golpe) indicaram relacionamento positivo com a tolerância política. Dentre as duas, a churchilliana apresentou maior significância e também maior correlação estatística com a tolerância política. Esse achado diverge do proposto por produções clássicas na área (McClosky 1964; Prothro e Grigg 1960), já que as pessoas que aceitam a demo- cracia enquanto valor abstrato e genérico se mostraram mais tolerantes do que as que de fato se mostraram comprometidas com esse regime político, quando confrontadas com a situação específica de apoio (ou não) ao golpe militar.

\section{Considerações finais}

Através da pesquisa desenvolvida, foi possivel responder aos objetivos propostos, já que as análises bivariadas permitem constatar que os niveis de tolerância política entre o público brasileiro estão de acordo com o que a literatura tem indicado: a maior parte da população não pode ser considerada tolerante ou intolerante, pois está localizada entre esses polos, desempenhando, assim, um pensamento e atitudes ambivalentes. (Moises 2008; Casalecchi 2016; Fuks et al. 2016; Fuks, Casalecchi e Ribeiro 2019; Ribeiro e Fuks 2019).

Por meio da análise das clivagens sociodemográficas, foi possivel verificar que a escolaridade se mostrou relevante, como já havia sido demonstrado por Sullivan et al. (1982), no entanto, a faixa etária foi o fator mais relevante, tradicionalmente apontado como tendo relação com a tolerância política, muito embora não tenhamos utilizado essa variável como principal interveniente no ato de tolerar. A pesquisa mostrou uma relação negativa entre idade e tolerância política.

Partindo para a questão mais proeminente do artigo, pois pretende responder ao objetivo principal, analisando a questão da adesão normativa à democracia, a partir da pergunta churchilliana, evidenciou-se, a partir dos dados, que a maior parte da população também apresenta um perfil ambivalente. Todas as variáveis sociodemográficas apresentaram significância, sendo a faixa de renda e a escolaridade as que têm maior relação com o apoio à democracia. Resultado, esse, parcialmente indicado por Booth e Seligson (2008), que não encontraram uma relevância tão alta na renda como nesse caso.

Embora não tenha se apresentado como altamente significativa, a variável faixa etária merece destaque, pois está inversamente relacionada à tolerância política, ou seja, os idosos tendem a ser mais democráticos e mais intolerantes. Esse 
achado corrobora com as teorias de que o apoio político é extremamente complexo, de forma que, muitas vezes, parece contraditório (Schedler e Sarsfield 2007; Booth e Seligson 2008; Sullivan, Piereson e Marcus 1982; Gibson 2006).

Ao estudar a adesão normativa através do apoio ou não ao golpe militar, obtivemos os mesmos resultados dos testes anteriores, isto é, a maior parte dos respondentes se posicionou contra o golpe, a resposta democrática nesse sentido. No entanto, como a pergunta só apresentava duas categorias, é impossivel captar respostas ambivalentes. Em relação às variáveis sociodemográficas, a escolaridade e faixa etária apresentam significância, a escolaridade com relação positiva e a faixa etária com relação negativa.

Finalmente, ao relacionarmos a adesão normativa à democracia com a tolerância política, através dos dois testes de regressão linear múltiplos, constatamos que, enquanto nas análises bivariadas a escolaridade aparece como significante, na regressão o $\mathrm{p}$-valor foi maior do que 0,05, provavelmente em razão da inserção de outras variáveis, que minimizaram o efeito da escolaridade. Por outro lado, a faixa etária, que já havia se mostrado significante nos testes bivariados, manteve esse mesmo resultado na regressão. Sexo e renda não foram significativos.

Ambas as variáveis de adesão à democracia apresentam significância e relação positiva com a tolerância política, sendo que a churchilliana apresentou correlação mais forte. Esse resultado difere do teorizado por Prothro e Grigg (1960) e McClosky (1964), que subestimaram a relação desse tipo de afirmação abstrata com o apoio a valores democráticos fundamentais.

As várias divergências encontradas entre os resultados desta pesquisa e grande parte da literatura precursora reafirmam a necessidade de pesquisas nesse sentido, já que grande parte dessas teorias foi desenvolvida em contexto de democracias com longa tradição, e a coleta de dados empíricos é essencial para que essas sejam postas à prova no contexto latino-americano e, especificamente, brasileiro.

\section{Referências}

Booth, John A.; Seligson, Mitchel A. 2009. The Legitimacy Puzzle in Latin America: Political Support and Democracy in Eight Nations. New York: Cambridge University Press.

Carlin, Ryan E.; Singer, Matthew M. 2011. "Support for Polyarchy in the Americas". Comparative Political Studies 44, 11 (junho): 1500-1527. https://doi. org/10.1177/0010414011407471

Casalecchi, Gabriel A. 2016. Legado democrático e atitudes democráticas na América Latina: efeitos diretos, indiretos e condicionais. Tese de Doutorado. Universidade Federal de Minas Gerais, Belo Horizonte, MG, Brasil.

Collier, David; Levitsky, Steven. 2011. "Democracy with Adjectives: Conceptual Innovation in Comparative Research". World Politics 49, 03 (abril): 430-451. https:// www.jstor.org/stable/25054009

Dahl, Robert A. 1961. Who Governs?: Democracy and Power in an American City. New Haven and London: Yale University Press.

Davis, James A. 1975. "Communism, Conformity, Cohorts, and Categories: American Tolerance in 1954 and 197273". American Journal of Sociology 81, 3 (novembro): 491-513. https://www.jstor.org/stable/2777641

Diamond, Larry; Linz, Juan. 1989. "Introduction: Politics, Society, and Democracy in Latin America". In Democravy in Developing Cointries, organizado por: Larry Diamond, Juan Linz e Seymour M. Lipset. Massachusetts: Data for Decision Making Project.

Easton, David. 1975. "A Re-Assessment of the Concept of Political Support". British Journal of Political Science 5, 4 (outubro): 435-457. https://Www.jstor.org/stable/193437

Falcão, Márcio; Garcia, Gustavo. 2020. "Ato pró-Bolsonaro em Brasilia reúne manifestantes em defesa de medidas inconstitucionais". G1, 31 de maio de 2020. https:// g1.globo.com/politica/noticia/2020/05/31/manifestantes-fazem-ato-em-brasilia-em-apoio-a-bolsonaro-e-em-defesa-de-medidas-inconstitucionais.ghtml

Fuks, Mario; Casalecchi, Gabriel A.; Quaresma, Guilherme; David, Flávia F. 2016. "Qualificando a adesão à democracia: quão democráticos são os democratas brasileiros?". Revista Brasileira de Ciência Política, 19 (janeiro/abril): 199-219. https://doi.org/10.1590/0103335220161908

Fuks, Mario; Casalecchi, Gabriel A., Ribeiro, Ednaldo A. 2019. "Determinantes contextuais da coesão do sistema de crenças democrático: evidências a partir da América Latina". Revista Brasileira de Ciência Política, 28 (janeiro/ abril): 7-32. https://doi.org/10.1590/0103-335220192801

Gibson, James L. 2006. "Enigmas of Intolerance: Fifty Years after Stouffer's Communism, Conformity, and Civil Liberties". Perspectives on Politics 4, 1 (fevereiro): 21-34. https://doi.org/10.1017/S153759270606004X

Gibson, James L. 2008. "Intolerance and Political Repression in the United States: A Half Century after McCarthyism". American Journal of Political Science 52, 1 (janeiro): 96-108. https://www.jstor.org/stable/25193799 
Gibson, James L. 2009. "Political intolerance in the context of democratic theory". In The Oxford Handbook of Political Science, editado por Rober E. Goodin. Oxford: Oxford University Press.

Lawrence, David G. 1976. "Procedural Norms and Tolerance: A Reassessment". The American Political Science Review 70, 1 (março): 80-100. https://doi. org/10.2307/1960325

McClosky, Herbert. 1964. "Consensus and Ideology in American Politics". The American Political Science Review 58, 2 (junho): 361-382. https://doi.org/10.2307/1952868

Marcus, George E.; Sullivan, John L.; Theiss-Morse, Elizabeth; Wood, Sandra L. 1995. With Malice Toward Some. Cambridge: Cambridge University Press.

Moises, José A. 2008. "Cultura política, instituições e democracia: lições da experiência brasileira". Revista Brasileira de Ciências Sociais 23, 66 (fevereiro): 11-43. https://doi.org/10.1590/S0102-69092008000100002

Norris, Pippa; Inglehart, Ronald. 2019. Cultural backlash: Trump, Brexit, and the rise of authoritarian populism. Cambridge: Cambridge University Press.

Nunn, Clyde Z.; Crockett, Harry J.; Williams, J. Allen. 1978. Tolerance and Nonconformity. San Francisco: Jossey-Bass.

Prothro, James W., Grig, Charles M. 1960. "Fundamental Principles of Democracy: Bases of Agreement and Disagreement". The Journal of Politics 22, 2 (maio): 276294. https://doi.org/10.2307/2127359

Ribeiro, Ednaldo A. 2010. "Mudança de valores e tolerância entre os brasileiros". Mediações 15, 1 (janeiro/junho): 220240. http://doi.org/10.5433/2176-6665.2010v15n1p220

Ribeiro, Ednaldo A.; Borba, Julian. 2019. "Tolerância Política no Brasil Recente: evolução de indicadores e condicionantes". Caderno CRH 32, 87: 641-657. https:// doi.org/10.9771/ccrh.v32i87.23749

Ribeiro, Ednaldo A.; Fuks, Mario. 2019. "Tolerância política no Brasil". Opinião Pública 25, 3 (setembro/dezembro): 531-555. http://doi.org/10.1590/1807-01912019253531

Schedler, Andreas, Sarsfield, Rodolfo. 2007. "Democrats with adjectives: Linking direct and indirect measures of democratic support". European Journal of Political Research 46, (junho): 637-659. https://doi.org/10.1111/ j.1475-6765.2007.00708.x

Sullivan, John L.; Piereson, James; Marcus, George E. 1982. Political Tolerance and American Democracy. Chicago: The University of Chicago Press.

Sullivan, John. L.; Transue, J. E. 1999. "The psychological underpinnings of democracy: A Selective Review of Research on Political Tolerance, Interpersonal Trust, and Social Capital". Annual Review of Psychology, 50, 1 (fevereiro): 625-650. https://doi.org/10.1146/annurev. psych.50.1.625

Stouffer, Samuel A. 1955. Communism, Conformity and Liberties: A Cross-Section of the Nation Speaks Its Mind. New York: Doubleday.

\section{Apêndices}

Apêndice 1: Testes pré-requisito para a regressão. https://github.com/NaiaraSandi1995/Victor-Naiara-ArtigoConversas.../commit/87ac3a3411d393bc83e313f83018543969422b97

Apêndice 2: Script. https://github.com/NaiaraSandi1995/Victor-Naiara-ArtigoConversas.../blob/main/ AP\%C3\%8ANDICE\%202\%20-\%20SCRIPT

Apêndice 3: Banco de dados. https://github.com/ NaiaraSandi1995/Victor-Naiara-ArtigoConversas.../ blob/main/lapop17.RData

\section{Victor Gabriel Menezes Menegassi}

Graduando em Ciências Sociais pela Universidade Estadual de Maringá (UEM), em Maringá, PR, Brasil.

\section{Naiara Sandi de Almeida Alcantara}

Graduada e Mestre em Ciências Sociais pela Universidade Estadual de Maringá (UEM), em Maringá, PR, Brasil. Atualmente é doutoranda em Ciência Política pela Universidade Federal do Paraná (UFPR), em Curitiba, PR, Brasil.

Os textos deste artigo foram revisados pela Zeppelini Publishers e submetidos para validação do(s) autor(es) antes da publicação 